\title{
Six months of exclusive breast feeding: how good is the evidence?
}

\section{Very low dietary iron intakes but normal haemoglobin levels at 8 months among fully breastfed infants starting solids at around 6 months}

\section{January 2011}

In their recent review Fewtrell et al. suggest that exclusive breastfeeding to 6 months could increase risk of anaemia. In view of this we would like to share some of our preliminary findings from a study currently being conducted in Brighton.

We are exploring the feeding practices and iron status of infants breastfed for at least six months. Most of these infants also conformed to the Government's recommendation to delay introducing solid foods until around 6 months and all were exclusively breastfed until at least 4 months. Even though our sample size was small, we found consistent evidence that in this group dietary iron intakes at 8 months were very low, with mean total iron intakes from all foods and drinks including breast milk being less than half the currently recommended levels (1). A sizeable proportion of participants actively avoided giving their children foods rich in bioavailable iron such as red meat. We found no evidence of low haemoglobin levels with all haemoglobin measurements being well within the normal range for this age group, as described by Emond et al (2).

It appears that despite low dietary iron intakes, haemoglobin levels are maintained at least until 8 months of age in this group of infants. Possible explanations for this may include sufficient iron endowment prenatally (in terms of maternal health and nutrition) and perinatal factors such as variations in cord clamping practices (3) or a possible over estimation of iron requirements in the 6-9 month age group. Publication of the results will follow shortly. 
1.COMA (1991). Dietary Reference Values for Food Energy and Nutrients for the United Kingdom, Report on health and social subjects, No. 41, HMSO. London

2.Emond, A. M., Hawkins N., et al. (1996). Haemoglobin and ferritin concentrations in infants at 8 months of age. Arch Dis Child 74 (1): 36-9

3.Chaparro, C.M., Neufeld L.M., Tena et al. (2006). Effect of timing of umbilical cord clamping on iron status in Mexican infants: a randomised controlled trial. Lancet 367: 1997-2004

Competing interests: P. Emmett has received small amounts of research funding from two companies manufacturing infant formula and infant foods in the past three years. $\mathrm{H}$. Rabe is the first author of the Cochrane Review on early versus slight delay of cord clamping in preterm infants.

Antiopi Ntouva, PhD Student / Dietitian

Pauline Emmett, Angela MacAdam, Heike Rabe, Sarath Ranganathan, Carol Williams, Imogen Rogers

School of Pharmacy and Biomolecular Sciences, University of Brighton

BMJ Group

Privacy policy

Website T \& Cs

Revenue Sources

Highwire Press

Feedback

Help

(c) 2012 BMJ Publishing Group Ltd 
Given URL is not allowed by the Application configuration.: One or more of the given URLs is not allowed by the Application configuration. It must match one of the Connect or Canvas URLs or domain must be the same as or a subdomain of one of the Application's base domains. 